\title{
Analysis of mycoplasmal pleural effusion by the polymerase chain reaction
}

\author{
Mitsuo Narita, Yoshihiro Matsuzono, Osamu Itakura, Satoshi Yamada, Takehiro Togashi
}

\begin{abstract}
Ten pediatric patients with mycoplasmal pleuritis were tested for the presence of Mycoplasma pneumoniae in pleural fluid by the polymerase chain reaction (PCR). Three of the four PCR positive cases left a persistent consolidation. The remaining one was an infant who required mechanical ventilation. PCR may be useful in predicting delayed resolution of roentgenographic abnormality.

(Arch Dis Child 1998;78:67-69)
\end{abstract}

Keywords: Mycoplasma pneumoniae; pleural effusion; polymerase chain reaction

Paediatrics, Hokkaido

University School of

Medicine

M Narita

Y Matsuzono

O Itakura

S Yamada

\section{Department of}

Paediatrics, Sapporo

City General Hospital, Sapporo, Japan

T Togashi

Correspondence to: Dr Mitsuo Narita,

Department of Paediatrics,

Hokkaido University School of Medicine, N 15 W 7,

Kita-ku, Sapporo 060, Japan

Accepted 21 July 1997

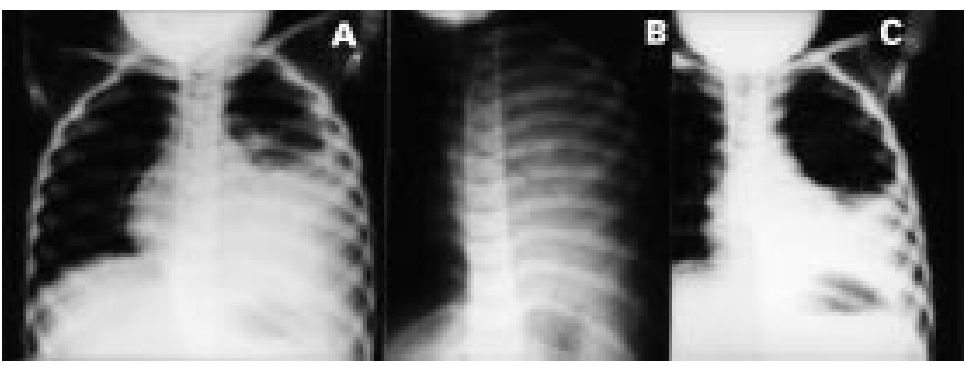

Figure 1 Chest radiographs of case 4. Panel A, taken on admission; panel B, taken immediately before drainage (four days after admission); panel $C$, taken at the recovery stage (one month after admission).

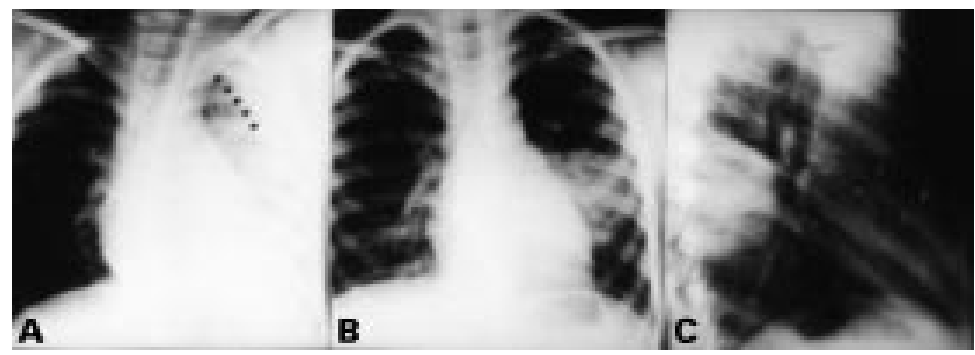

Figure 2 Chest radiographs of case 9. Panel A, taken before drainage (10 days after admission), left decubital view. Arrowheads indicate the retention of fluid; panels $B$ and $C$, taken at the recovery stage (two months after admission). longed clinical course, these cases are briefly illustrated below.

\section{CASE 4}

A 2 year old previously healthy girl was referred to the hospital because of a high fever and severe cough that had lasted for a week. On admission, a chest radiograph revealed a massive pleural effusion in the left lung (fig 1A) and a thoracocentesis yielded a serous fluid (sample 1). Treatment was started with intravenous cefotiam and oral erythromycin. Despite repeated removal of the fluid, a chest radiograph taken on the fourth day revealed an entirely opaque left lung field with a deviation of the mediastinum to the right (fig 1B). A closed chest tube thoracostomy was performed which yielded a bloody fluid (sample 2). The treatment was changed to intravenous cefotaxime and intravenous clindamycin with the addition of oral clarithromycin. A chest radiograph taken one month after admission still showed a dense consolidation (fig 1C).

\section{CASE 7}

An 11 year old boy having neuronal ceroid lipofuscinosis was admitted to the hospital because of a fever and cough. A pleural effusion in the right lung was noticed five days after admission, and a thoracocentesis yielded a bloody pleural fluid without any noticeable mechanical injury. He subsequently required a left thoracocentesis on the next day. Although his condition improved with intravenous minocycline, a residual consolidation was still observed in the right lung three months after discharge.

CASE 8

An 11 month old boy with Down's syndrome was admitted to the hospital because of a fever and cough. He was intubated due to poor oxygenation and an arterial oxygen of 6.67-8.00 $\mathrm{kPa}$ was maintained under $100 \%$ oxygen supplement. A pleural effusion in the right lung became evident four days after admission. The patient gradually recovered with intravenous minocycline without showing any residual abnormalities on a chest radiograph.

\section{CASE 9}

A 5 year old previously healthy boy was referred to the hospital because of fever and a cough. Intravenous clindamycin was administered. A small pleural effusion was noticed in the left lung two days after admission and intravenous minocycline along with oral clarithromycin was added to the treatment. Despite these treatments, the fluid collection pro- 
Table 1 Characteristics of the 10 cases, pleural fluid, and results of PCR

\begin{tabular}{|c|c|c|c|c|}
\hline Case & 1 & 2 & 3 & 4 \\
\hline Age (years)/sex & $12 / \mathrm{M}$ & $3 / \mathrm{M}$ & $15 / \mathrm{F}$ & $3 / \mathrm{F}$ \\
\hline Affected side & Right & Left & Right & Left \\
\hline Day of appearance ${ }^{\star}$ & $<0(0)$ & $2(2)$ & $<0(6)$ & $<0(0),(5)$ \\
\hline Removal of effusions (volume in $\mathrm{ml}$ ) & Drainage & $\begin{array}{l}\text { Thoracocentesis } \\
(100)\end{array}$ & $\begin{array}{l}\text { Thoracocentesis } \\
\text { (340) }\end{array}$ & $\begin{array}{l}\text { Thoracocentesis (repeated), } \\
\text { drainage }\end{array}$ \\
\hline \multicolumn{5}{|l|}{ Antimycoplasmal antibody titre $†$} \\
\hline Acute & $<40$ & 8 & $<40$ & $<40$ \\
\hline Highest observed & 160 & 256 & 80 & 20480 \\
\hline Pleural fluid & & & & (Sample 1) \\
\hline Appearance & Serous & Serous & Serous & Serous \\
\hline Protein $(\mathrm{g} / \mathrm{l})$ & 49 & 26 & 46 & 44 \\
\hline Lactate dehydrogenase (U/1) & 3236 & & 611 & 11670 \\
\hline Cell count $\left(/ \mathrm{mm}^{3}\right)$ & 46 & & & Numerous \\
\hline Sample volume tested $(\mathrm{ml})$ & 4.0 & 25 & 3.4 & 10 \\
\hline Other involvement $\ddagger$ & $\begin{array}{l}\text { Liver } \\
\quad \text { dysfunction }\end{array}$ & $\begin{array}{l}\text { Liver dysfunction, } \\
\text { skin rash }\end{array}$ & None & None \\
\hline $\begin{array}{l}\text { Resolution of chest } \\
\text { roentgenograms } \ \text { (months) } \\
\text { PCR\# }\end{array}$ & $\begin{array}{l}0.7 \\
(-)\end{array}$ & $\begin{array}{l}0.5 \\
( \pm)\end{array}$ & $\begin{array}{l}0.5 \\
(-)\end{array}$ & $\begin{array}{l}12 \\
(+)\end{array}$ \\
\hline
\end{tabular}

* The day of admission was denoted as day 0 . The day of removal was shown in parentheses. $<0$ means that the effusion was already present on admission.

+ Particle agglutination test was used for all cases except for case 2 in which complement fixation test was used.

$\ddagger$ Liver dysfunction, maximum alanine aminotransferase value (U/1); 210 in case 1,2004 in case 2,478 in case 5,342 in case 10.

gressed (fig 2A). Ten days after admission, a thoracocentesis was performed followed by administration of intravenous dexamethasone, which resulted in disappearance of the fever. A segmental consolidation remained at two months after admission in the absence of signs of active inflammation (fig $2 \mathrm{~B} / \mathrm{C}$ ).

With the exception of case 8 the acute illness in these four cases was no more severe than in the other six cases. Apparently none of the 10 cases were subject to respiratory morbidity beyond the acute illness, although extensive investigations such as bronchography were not performed.

\section{Methods}

The characteristics of the pleural effusions are listed in table 1 . The sample volume tested, which is shown in table 1 , is an approximate

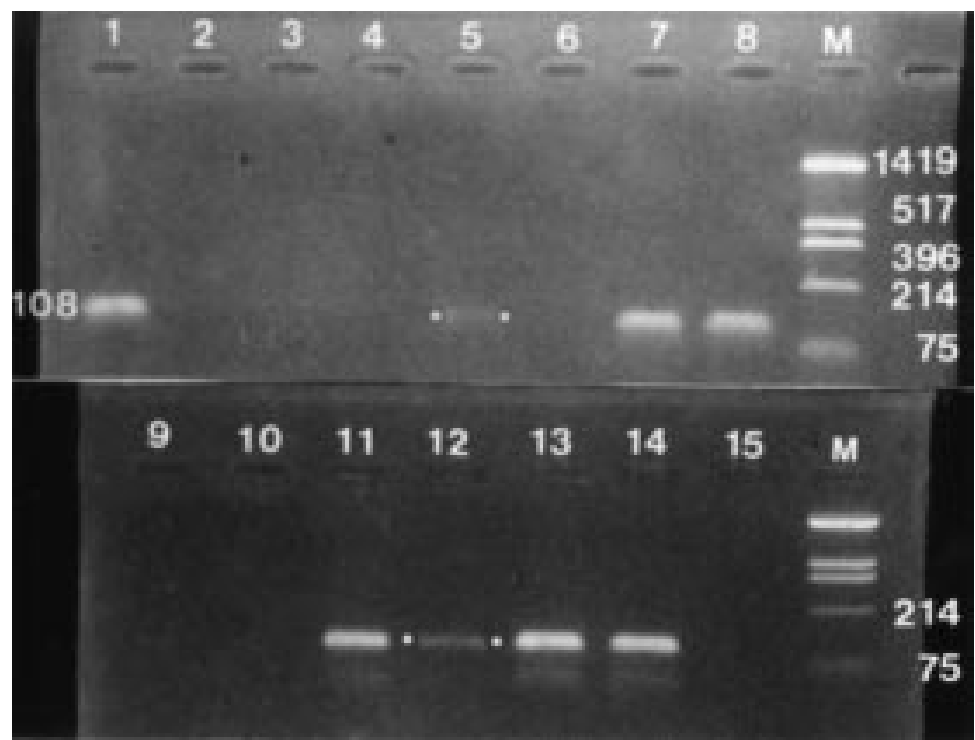

Figure 3 Results of PCR using pleural fluid samples. Ethidium bromide stained agarose gels. Lane 1, positive control (1 pg of whole chromosomal DNA from a strain $M$ pneumoniae IID 817); lane 2, negative control (a buffer control); lane 3, negative control (a sham operation with water); lane 4, pleural fluid sample from case 1; lane 5, case 2; lane 6 , case 3; lane 7, case 4 (sample 1); lane 8 , case 4 (sample 2); lanes $M$, a size marker (pUC 19 digested with Hinf I); lane 9, case 5; lane 10, case 6; lane 11, case 7 (right lung); lane 12, case 7 (left lung); lane 13, case 8; lane 14, case 9; lane 15, case 10. Numbers at the right are base pairs. Number 108 at the left indicates the size of the expected band. Closed squares on lanes 5 and 12 indicate the amplified bands which are only faintly visible. volume of the material that was actually used in one polymerase chain reaction (PCR) experiment, being calculated from the final volume of the DNA solution. Amplifications were carried out essentially by the same methodology as described elsewhere. ${ }^{3}$ General precautions were undertaken to avoid cross contamination. Eleven pleural fluid samples from 11 patients with pleuritis in which causes other than $M$ pneumoniae infection were identified served as controls.

\section{Results}

The results of PCR amplification with the 12 pleural fluid samples from the 10 patients with mycoplasmal infection are shown in fig 3 and in table 1 . Of these, two sequential samples from case 4 , samples from cases 7,8 , and 9 yielded a strongly positive band of $M$ pneumoniae, while negative results were obtained with the samples from cases 1, 3, 5, 6, and 10. A sample from case 2 showed a faintly positive band that was scarcely visible, whose result was considered as indeterminate. None of the 11 pleural fluid samples from the controls yielded a positive band.

\section{Discussion}

A remarkable finding in this study is the strongly positive bands of $M$ pneumoniae DNA which were observed using the samples from cases $4,7,8$, and 9 . One major concern is that two of the samples with the positive PCR results were bloody. In case 4 , sample 1 (apparently serous fluid) had already contained the genome of $M$ pneumoniae before it became bloody, and in case 7 , a serum sample which was obtained at the same time of thoracocentesis was performed did not yield a positive band. These facts suggest that the positive PCR results can be considered to represent a massive invasion of the pleural space by this organism rather than simple contamination with the organism from blood.

Three explanations can be offered for the differences concerning the PCR results. First, the PCR positive and negative cases arise from substantially different pathophysiological 
Table 1 Continued

\begin{tabular}{|c|c|c|c|c|c|c|c|}
\hline & 5 & 6 & \multicolumn{2}{|l|}{7} & 8 & 9 & 10 \\
\hline & $10 / \mathrm{M}$ & $7 / \mathrm{M}$ & \multicolumn{2}{|l|}{$11 / \mathrm{M}$} & $0.9 / \mathrm{M}$ & $5 / M$ & $4 / F$ \\
\hline & Left & Right & \multicolumn{2}{|c|}{ Bilateral } & Right & Left & Bilateral \\
\hline & $4(4)$ & $<0(0)$ & \multicolumn{2}{|c|}{$5(5), 6(6)$} & $4(8)$ & $2(10)$ & $<0(1)$ \\
\hline & $\begin{array}{l}\text { Thoracocentesis } \\
\text { (120) }\end{array}$ & $\begin{array}{l}\text { Thoracocentesis } \\
(>100)\end{array}$ & \multicolumn{2}{|c|}{$\begin{array}{l}\text { Thoracocentesis, } \\
\text { drainage }\end{array}$} & $\begin{array}{l}\text { Thoracocentesis } \\
\text { (85) }\end{array}$ & $\begin{array}{l}\text { Thoracocentesis } \\
\text { (190) }\end{array}$ & $\begin{array}{l}\text { Thoracocentesis } \\
(130)\end{array}$ \\
\hline & $<40$ & 320 & \multicolumn{2}{|l|}{$<40$} & 2560 & $<40$ & 80 \\
\hline & 1280 & 640 & 160 & & 2560 & 1280 & 640 \\
\hline \multirow{5}{*}{$\begin{array}{l}\text { (Sample 2) } \\
\text { Bloody }\end{array}$} & & & (Right) & \multicolumn{2}{|l|}{ (Left) } & & (Right) \\
\hline & Serous & Serous & Bloody & Serous & Serous & Serosanguinous & Serous \\
\hline & & & 26 & & 23 & 46 & 26 \\
\hline & 2650 & & 914 & & & 2387 & 1680 \\
\hline & & & 900 & & 2525 & 1047 & \\
\hline \multirow[t]{2}{*}{8} & 8.5 & 17 & 10 & 10 & 10 & 3.6 & 3.6 \\
\hline & $\begin{array}{l}\text { Liver dysfunction, } \\
\text { skin rash, SIADH }\end{array}$ & None & \multicolumn{2}{|l|}{ None } & None & None & Liver dysfunction \\
\hline$(+)$ & $\begin{array}{l}0.5 \\
(-)\end{array}$ & $\begin{array}{l}0.7 \\
(-)\end{array}$ & $\begin{array}{l}>3 \\
(+)\end{array}$ & $( \pm)$ & $\begin{array}{l}1 \\
(+)\end{array}$ & $\begin{array}{l}>2 \\
(+)\end{array}$ & $\begin{array}{l}0.5 \\
(-)\end{array}$ \\
\hline
\end{tabular}

$\int$ Time interval from the admission to the normalisation of the chest radiographs.

$\#(+)=$ positive; $( \pm)=$ indeterminate $(-)=$ negative.

$\mathrm{SIADH}=$ syndrome of inappropriate secretion of antidiuretic hormone.

mechanisms, that is, the former being caused by the direct invasion by this organism, and the latter by the indirect mechanisms. Second, these are within a continuum of the same disease, the clinical severity being simply proportional to the amounts of the organism in the fluid as represented by the PCR positivity. Third, an unrecognised superinfection such as by adenovirus type $7^{4}$ predisposed these patients to have severe lung damage secondarily resulting in an active state of $M$ pneumoniae replication, or vice versa.

The exact nature of the persistent consolidation could not be clarified in this study. Due to the fundamentally benign nature of the infection, pathological features of the affected lung have been described only in a few articles. ${ }^{5-7}$ Within this experience, severe and fatal cases were associated with interstitial fibrosis. ${ }^{67} \mathrm{We}$ believe that the persistent consolidation that was observed in our study may represent a rather milder presentation of localised fibrotic changes.

In conclusion, the positive PCR results using pleural fluid samples in mycoplasmal pleuritis were strongly associated with residual radiographic abnormality. In this regard, PCR may provide a predictive result with a single acute phase specimen.

We thank the following for providing us with samples: Drs $\mathrm{N}$ Satake and Y Koga of Muroran Nikko Memorial Hospital (case 2), T Machida and Z Miyazato of Okinawa Nakagami Hospital 2), T Machida and $Z$ Miyazato of Okinawa Nakagami Hospital
(cases 3 and 4), S Kikuoka and H Meguro of Teikyo University (cases 3 and 4), S Kikuoka and H Meguro of Teikyo University
Ichihara Hospital (case 5), T Hyuga of Kushiro Rousai HospiIchihara Hospital (case 5), T Hyuga of Kushiro Rousai Hospi-
tal (case 6), M Kojyo and T Ogawa of Oita Medical University tal (case 6), M Kojyo and T Ogawa of Oita Medical University
(case 7), M Kikuchi of Hitachi General Hospital (case 8), K (case 7), M Kikuchi of Hitachi General Hospital (case 8), K
Uetake of Sapporo Tenshi Hospital (case 9), and A UmetsuUetake of Sapporo Tenshi Hospital (case 9), and A Umetsu-
Okamura of Sapporo Kounan Hospital (case 10). We also thank Professor K Kobayashi of the Department of Paediatrics, Hokkaido University School of Medicine, for his critical review of this manuscript.

1 Nagayama Y, Sakurai N, Yamamoto K. Clinical observations of children with pleuropneumonia due to Mycoplasma pneumoniae. Pediatr Pulmonol 1990;8:182-7.

2 Narita M, Matsuzono Y, Togashi T, et al. DNA diagnosis of central nervous system infection by Mycoplasma pneumoniae. Pediatrics 1992;90:250-3.

3 Narita M, Matsuzono Y, Itakura O, et al. Survey of mycoplasmal bacteremia detected in children by polymerase chain reaction. Clin Infect Dis 1996;23:522-5.

4 Aiello LF, Luby JP. Concomitant mycoplasma and adenovirus infection in a family. Am $\mathcal{F}$ Dis Child 1974;128:874-7.

5 Rollins S, Colby T, Clayton F. Open lung biopsy in Mycoplasma pneumoniae pneumonia. Arch Pathol Lab Med 1986;110:34-41.

6 Maisel JC, Babbitt LH, John TJ. Fatal Mycoplasma Maisel JC, Babbitt LH, John TJ. Fatal Mycoplasma
pneumoniae infection with isolation of organisms from pneumoniae infection with isolat

7 Kaufmann JM, Cuvelier CA, van der Straeten $M$. Mycoplasma pneumonia with fulminant evolution into diffuse interstitial fibrosis. Thorax 1980;35:140-4. 